\title{
Functional Magnetic Resonance Imaging Evidence for
}

Abnormalities in Response Selection in Attention Deficit Hyperactivity Disorder: Differences in Activation Associated with Response Inhibition but Not Habitual Motor Response

\author{
Stacy J. Suskauer ${ }^{1,2}$, Daniel J. Simmonds ${ }^{1}$, Sunaina Fotedar ${ }^{3}$, Joanna G. Blankner ${ }^{4}$, James \\ J. Pekar ${ }^{1,2}$, Martha B. Denckla ${ }^{1,2}$, and Stewart H. Mostofsky ${ }^{1,2}$ \\ ${ }^{1}$ Kennedy Krieger Institute, Baltimore, MD \\ 2Johns Hopkins University School of Medicine \\ ${ }^{3}$ USM Business Systems, Chantilly, VA \\ ${ }^{4}$ University of Tennessee College of Medicine
}

\begin{abstract}
Impaired response inhibition is thought to be a core deficit in attention deficit hyperactivity disorder (ADHD). Prior imaging studies investigating response inhibition in children with ADHD have used tasks involving different cognitive resources, thereby complicating the interpretation of their findings. In this study, a classical go/no-go task with a well-ingrained stimulus-response association (green $=$ go; red $=$ no-go) was used in order to minimize extraneous cognitive demands. Twenty-five children with ADHD and 25 typically developing (TD) children between the ages of 8 and 13 years and group-matched for IQ and performance on the go/no-go task were studied using event-related functional magnetic resonance imaging (fMRI). Analyses were used to examine differences in activation between the ADHD and TD groups for "go" (habitual motor response) and "nogo" (requiring inhibition of the motor response) events. Region-of-interest analyses revealed no between-group difference in activation in association with "go" events. For "no-go" events, the children with ADHD demonstrated significantly less activation than did TD controls within a network important for inhibiting a motor response to a visual stimulus, with frontal differences localized to the pre-supplementary motor area. Although blood oxygenation level-dependent fMRI data show no differences between children with ADHD and TD children in association with a habituated motor "go" response, during "no-go" events, which require selecting not to respond, children with ADHD show diminished recruitment of networks important for response inhibition. The findings suggest that abnormalities in circuits important for motor response selection contribute to deficits in response inhibition in children with ADHD and lend support to the growing awareness of ADHD-associated anomalies in medial frontal regions important for the control of voluntary actions.
\end{abstract}

\section{Introduction}

Deficient response inhibition has been highlighted as an important and pervasive feature of attention deficit hyperactivity disorder (ADHD) (Nigg, 2001; Barkley, 1997). Children with ADHD demonstrate impaired inhibitory control in emotional regulation (Berlin, Bohlin,

Reprint requests should be sent to Stewart H. Mostofsky, Kennedy Krieger Institute, 707 North Broadway, Baltimore, MD 21205, or via mostofsky@kennedykrieger.org. 
Nyberg, \& Janols, 2004; Walcott \& Landau, 2004), oculomotor function (Hanisch, Radach, Holtkamp, Herpertz-Dahlmann, \& Konrad, 2006; Feifel, Farber, Clementz, Perry, \& AnlloVento, 2004; Mostofsky, Lasker, Cutting, Denckla, \& Zee, 2001), and on skeletomotor tasks requiring the cessation of an ongoing activity (Overtoom et al., 2002; Stevens, Quittner, Zuckerman, \& Moore, 2002; Nigg, 1999) or withholding of a prepotent response (Tamm, Menon, Ringel, \& Reiss, 2004; Durston et al., 2003; Mostofsky, Newschaffer, \& Denckla, 2003). As such, an understanding of the neural mechanisms underlying deficient response inhibition may provide critical information for the basis of future diagnostic, prognostic, and treatment strategies for ADHD.

Response inhibition is commonly studied using go/no-go and stop-signal tasks. Classically, go/no-go tasks consist of two stimuli, one representing "go" and a second representing "nogo." The subject is typically requested to perform a motor action in response to the frequent appearance of "go" stimuli and to withhold that prepotent motor response when infrequently a "no-go" stimulus appears. Thus, the subject is required to choose a response (including withholding of a response) upon the appearance of the stimulus. Variations of the task itself may influence neural mechanisms required for accurate task completion. For example, increasing the number or complexity of stimuli used in a go/no-go task can create a larger cognitive load for discriminating among stimuli to determine which motor response is indicated. In this regard, there is evidence that increased cognitive demand associated with a go/no-go task results in recruitment of additional prefrontal and posterior cortical regions during inhibition of a motor response (Mostofsky, Schafer, et al., 2003). Task demands may also influence the neural correlates of stop-signal tasks, which classically consist of a "go" stimulus, also paired with a motor action, and a "stop" stimulus, which infrequently appears after the "go" stimulus. When the "stop" signal is delivered, the subject is required to abort the motor response that was theoretically initiated upon appearance of the "go" stimulus; this is in contrast to the go/no-go task, in which the response is chosen upon stimulus appearance. Thus, the neural correlates of response inhibition also may differ between go/no-go and stop-signal paradigms.

Findings from imaging studies of children and adults performing go/no-go and stop-signal tasks highlight the importance of frontal systems in response inhibition, including frontalsubcortical (striatal and cerebellar) circuits involving both premotor (Picton et al., 2006; Mostofsky, Schafer, et al., 2003; Connolly, Goodale, Desouza, Menon, \& Vilis, 2000) and prefrontal regions (Rubia et al., 2006; Booth et al., 2003, 2004) as well as frontal-parietal networks (Blasi et al., 2006; Wager et al., 2005). Within the frontal lobes, studies have identified varying areas of activation in association with response inhibition, most frequently within the rostral supplementary motor area (pre-SMA) (Floden \& Stuss, 2006; Garavan, Hester, Murphy, Fassbender, \& Kelly, 2006; Mostofsky, Schafer, et al., 2003; Humberstone et al., 1997), the dorsolateral prefrontal cortex (Garavan et al., 2006; Bellgrove, Hester, \& Garavan, 2004; Hester et al., 2004), and the right inferior frontal cortex (Aron, Robbins, \& Poldrack, 2004; Rubia et al., 2001; Garavan, Ross, \& Stein, 1999; Konishi et al., 1999). Variability in findings among studies may be a reflection of differences in task requirements.

Given well-defined deficits in motor control (Mahone et al., 2006; Mostofsky, Newschaffer, et al., 2003; Denckla \& Rudel, 1978) and executive function (Goldberg et al., 2005; Mahone, Koth, Cutting, Singer, \& Denckla, 2001; Reader, Harris, Scheuerholz, \& Denckla, 1994) in children with ADHD, deviations in the premotor and prefrontal systems are likely candidates for the observed abnormalities in response inhibition in these children. Prior studies (Durston, Mulder, Casey, Ziermans, \& van Engeland, 2006; Pliszka et al., 2006; Smith, Taylor, Brammer, Toone, \& Rubia, 2006; Rubia, Smith, Brammer, Toone, \& Taylor, 2005; Vaidya et al., 2005; Schulz et al., 2004; Tamm et al., 2004; Durston et al., 2003) have used event-related functional magnetic resonance imaging (fMRI) and variations/elaborations of the classical go/no-go and 
stop-signal tasks in small groups of children with ADHD; these studies revealed differences in fMRI activation within varying structures in frontal-subcortical and frontal-parietal networks. Given the evidence that the neural correlates of response inhibition are task dependent (Mostofsky, Schafer, et al., 2003), the variability in findings across prior ADHD studies may be due to differences in task requirements, with activation of fronto-striatal circuits varying depending upon the demands of the behavioral task.

Some variations of the classic go/no-go task used in studies of children with ADHD involve more than two stimuli. For example, Durston et al. (2003) used a task incorporating multiple cartoon characters as stimuli and a 3:1 go/no-go ratio. With this task, children with ADHD showed greater activation than controls in the right superior frontal gyrus and inferior parietal cortex and in bilateral posterior cingulate gyri, precuneus, and occipital cortex; these children with ADHD showed reduced activation in the left caudate nucleus. In a more recent cohort studied with the same task, children with ADHD showed decreased activation in the left premotor cortex, inferior frontal gyrus, and anterior cingulate gyrus, right middle/superior frontal gyrus, and left inferior parietal lobule (Durston et al., 2006). Schulz et al. (2004) used a task with six letters serving as stimuli; with a 5:1 go/no-go ratio, children with ADHD showed increased activation compared to controls in the left anterior cingulate gyrus, right precuneus, and bilateral middle/inferior frontal gyri and inferior parietal lobules. In this cohort, children with ADHD showed decreased activation in the right precentral, inferior temporal, and lingual gyri, as well as in the left hippocampus and bilateral cerebellum. Tasks such as those used in these studies that include multiple novel stimulus-response associations require that the child hold recently learned rules in memory during task completion; thus, activation associated with response inhibition may include regions important for the use of working memory to guide inhibitory behavior. Additionally, tasks involving discrimination among multiple stimuli may be more likely to involve activation of the anterior cingulate, which has a well-established role in error detection, as was the case in two of these three studies.

Other go/no-go tasks used in fMRI studies of children with ADHD require subjects to select from among three possible responses (two motor responses, such as pushing button 1 or button 2 , or withholding from responding) depending upon the stimulus presented. Using a task with a 3:1 go/no-go ratio and three letters representing go and no-go stimuli, Tamm et al. (2004) found that children with ADHD showed increased activation in the left middle/inferior/superior temporal gyrus and decreased activation in the right cingulate cortex extending to the SMA. Smith et al. (2006) used arrows as stimuli and an 8:1 go/no-go ratio and showed decreased activation in the left rostral mesial frontal cortex among children with ADHD. Vaidya et al. (2005) used a flanker task requiring the child to discriminate among multiple objects viewed simultaneously; in this cohort, no statistically significant between-group differences in activation were demonstrated.

Pliszka et al. (2006) and Rubia et al. (2005) both used stop-signal tasks with three possible motor responses. With a task using arrows as stimuli and a 4:1 go/stop ratio, children with ADHD showed decreased activation in the right orbitoinferior prefrontal cortex (Rubia et al., 2005); whereas, with a task using letters as stimuli and a 3:1 go/stop ratio, children with ADHD showed decreased activation in the anterior cingulate cortex (Pliszka et al., 2006). Tasks with multiple stimuli and several possible responses, such as these go/no-go and stop-signal tasks, add further demands on systems important for motor planning and maintaining stimulusresponse associations necessary to guide response inhibition/selection, which may be reflected in the neural activation patterns demonstrated in these studies.

Taken together, these studies provide evidence for ADHD-associated differences in the activation within frontal-subcortical and frontal-parietal circuits during response inhibition. There is, however, substantial variability across these studies both in the localization and 
direction of ADHD-associated differences in activation within these regions, which may relate to differences in tasks. Given the range of findings across studies, a methodological approach in which task design is systematically varied would be useful for elucidating the neural mechanisms underlying impaired response inhibition in ADHD. As a first step, it would be advantageous to focus on the components solely involved in selection (including inhibition) of relatively simple responses, thus focusing on response inhibition in this specific domain and minimizing involvement of more complicated neural systems necessary for regulation of cognition and behavior. As such, the goal of the current study was to further examine the neural mechanisms underlying motor response inhibition in children with ADHD as compared to their typically developing (TD) peers while attempting to minimize the involvement of more complicated neural systems necessary for regulation of other aspects of cognition and behavior (e.g., working memory). In contrast to the prior studies, each of which included multiple go stimuli in addition to the no-go or stop stimulus, we chose to use a classic go/no-go task design (Mostofsky, Schafer, et al., 2003), in which there are only two stimuli, thereby reducing the cognitive load with regard to discriminating among stimuli. The task was further simplified by minimizing the need for newly learned rules through the use of stimuli incorporating the familiar stimulus-response association of green $=$ go and red $=$ no-go, which is introduced in early childhood through books and songs and is inherent to age-related games by the developmental stage of the children within our cohort. This, combined with rapid stimulus presentation in an event-related design, allows for examination of distinctions in motor response and motor response inhibition between children with and without ADHD, while minimizing the impact of extraneous cognitive variables. A variation of this task has been used previously in an fMRI study of 48 healthy adults which revealed no-go associated activation primarily in the rostral supplementary motor area, or pre-SMA (Mostofsky, Schafer, et al., 2003), which is consistent with evidence from lesion, electrophysiologic, and imaging studies that the pre-SMA is involved in response preparation and selection (including selecting to inhibit a response) (Picton et al., 2006; Connolly et al., 2000; Matsuzaka, Aizawa, \& Tanji, 1992).

Activation in the pre-SMA is also associated with less intraindividual response time variability (i.e., more consistency) during performance of a go/no-go task (Simmonds et al., 2007). This is particularly relevant to children with ADHD who demonstrate abnormalities in response preparation, with several studies revealing increased response time variability (Klein, Wendling, Huettner, Ruder, \& Peper, 2006; Verte, Geurts, Roeyers, Oosterlaan, \& Sergeant, 2006; Hurks et al., 2005; Klimkeit, Mattingley, Sheppard, Lee, \& Bradshaw, 2005; Lijffijt, Kenemans, Verbaten, \& van Engeland, 2005; Mostofsky et al., 2001; Nigg, 1999). Across both $\mathrm{ADHD}$ and TD groups, there is a strong correlation between inhibitory performance and response time variability (Simmonds et al., 2007; Verte et al., 2006; Nigg, 1999), and abnormalities in the pre-SMA may contribute to impaired behavioral control in ADHD, including deficits in response preparation and inhibition. Decreased cortical thickness localized to the medial frontal wall in children with ADHD (Shaw et al., 2006) further implicates the pre-SMA in deficits associated with ADHD. Therefore, we hypothesized that during performance of a response inhibition task in which cognitive demands were otherwise minimized, differences within the frontal regions would be localized to the pre-SMA, and children with ADHD, relative to TD controls, would demonstrate less ability to rely upon the pre-SMA and associated subcortical structures for response inhibition under these conditions.

Additional potential sources of variability in prior fMRI studies include variations in sample sizes and behavioral accuracy between groups. The number of subjects with ADHD in the prior studies ranged from 7 to 17, with four of the studies including 10 or fewer children with ADHD (Vaidya et al., 2005; Schulz et al., 2004; Durston et al., 2003; Rubia, Overmeyer, et al., 1999). In some of the previous studies, statistically significant differences in task error rate between groups were present (Tamm, Menon, \& Reiss, 2006; Booth et al., 2005; Vaidya et al., 
2005; Schulz et al., 2004; Tamm et al., 2004; Durston et al., 2003), whereas in other studies, there were no differences in behavioral accuracy (Pliszka et al., 2006; Smith et al., 2006). In the setting of unequal accuracy between children with ADHD and their controls, differences in group activation may be related to disparity in task difficulty (struggles to perform the task) (Schlaggar et al., 2002). For these reasons, the present cohort included relatively large groups of children with ADHD and TD children (25 children per group) who demonstrated statistically equivalent performance on the go/no-go task.

\section{Methods}

\section{Participant Selection}

Twenty-five children with ADHD and 25 sex-matched TD children (controls) were enrolled in this study. All children were between the ages of 8 and 13 years. Participants were recruited from several sources, including outpatient clinics at the Kennedy Krieger Institute, advertisements placed with community-wide service groups, volunteer organizations, local schools and medical institutions, and by word of mouth. All children had a full-scale IQ greater than or equal to 85 based on present performance on Wechsler Intellectual Scale for Children (WISC) third or fourth edition (Wechsler, 1991, 2003). None of the children had a history of speech/language disorder or a reading disability (RD); all had a standard score of 85 (16th percentile) or higher on the Basic Reading subtest of the Wechsler Individual Achievement Test (WIAT) (Wechsler, 1992) or the Word Reading subtest of the WIAT-II (Wechsler, 2002).

The structured parent interview, Diagnostic Interview for Children and Adolescents-Fourth edition (DICA-IV) (Reich, 2000) and an ADHD-specific broad behavior rating scale (Conners' Parent and Teacher Rating Scales_-Revised [CPRS-R, CTRS-R, long form]; Conners, 1997) were used to confirm ADHD diagnosis. The CPRS-R and DICA-IV were also used to evaluate ADHD subtype. Seventeen children with ADHD met criteria for ADHD-combined type, six met criteria for ADHD-predominantly inattentive type, and two met criteria for ADHDpredominantly hyperactive/impulsive type.

The DICA-IV was also used to examine for the presence of other psychiatric disorders in all children. Children with ADHD who met criteria for comorbid conduct disorder, mood disorder, generalized anxiety disorder, separation anxiety disorder, or obsessive-compulsive disorder were excluded from this study. Children with comorbid oppositional defiant disorder (ODD) or simple phobia were included; 11 subjects with ADHD met criteria for ODD, and 5 children with ADHD met criteria for simple phobia (including 2 of the children with comorbid ODD). None of the subjects had any history of other neurological disorders, including Tourette syndrome. Twelve of the children with ADHD were being treated with stimulant medication, and their parents were requested to withhold the medication the day of and the day prior to testing. Withholding of medication as instructed was confirmed for all children by parent report on the day of the scanning procedure. No children with ADHD were taking additional psychoactive medications.

Children were included in the TD control group only if they did not meet ADHD diagnostic criteria on any of the administered rating scales and questionnaires. None of the TD children met criteria for any psychiatric disorder on the DICA-IV, with the exception of two children who met criteria for simple phobia. None of the control children were taking psychoactive medications.

This study was approved by the Johns Hopkins Medicine Institutional Review Board. For all subjects, written consent was obtained from a parent or guardian, and assent was obtained from the participating child. 


\section{fMRI Go/No-go Paradigm}

Children completed a simplified go/no-go task similar to that described in a prior published study of adults (schematic of task available in Mostofsky, Schafer, et al., 2003). Subjects were instructed to press a button with the right index finger as quickly as possible each time a green spaceship appeared but not to press the button if a red spaceship appeared; a response was allowed until the next stimulus appeared. Each trial consisted of either a green (go) or a red (no-go) spaceship presented at a rapid pace (stimulus duration of $300 \mathrm{msec}$ ), with sequential stimuli separated by a white crosshair fixation point using an interstimulus interval (ISI) of $1500 \mathrm{msec}$. The ratio of go to no-go stimuli was 3:1; between three and seven green ships appeared sequentially, whereas red ships occurred either individually or as two in a row. Consequently, no-go stimuli were effectively jittered, with the interval between no-go stimuli varying depending on the number of preceding go stimuli. Four rest periods in which a crosshair remained on screen for $10 \mathrm{sec}$ occurred at irregular intervals during each run, and each run started and ended with $10 \mathrm{sec}$ of rest. Every subject completed an initial practice trial in order to display comprehension of the instructions; this was followed by two blocks of the paradigm, each of which contained 95 go and 32 no-go events (3:1 go/no-go ratio) and lasted approximately $5 \mathrm{~min}$. The stimuli were displayed on a screen at the rear of the scanner and viewed in a mirror mounted at $45^{\circ}$ on the head coil. Stimulus presentation and response logging were completed using E-prime (Psychology Software Tools, Pittsburgh, PA, USA).

\section{Scanning Procedure}

Scanning was completed in a 1.5-T ACS-NT Powertrack 6000 MRI scanner (Philips Medical Systems) using body coil transmission and quadrature end-capped head-coil reception. T1weighted high-resolution anatomical images were acquired for each participant and used in the creation of cost function masks. For the functional images, coronally oriented volumes were acquired every $2.5 \mathrm{sec}$ using single-shot echo-planar imaging (EPI) $64 \times 64$ voxel matrix, 3.59 $\times 3.59 \times 4.5 \mathrm{~mm}$ voxels, TE $40 \mathrm{msec}$, and flip angle $90^{\circ}$. Each volume was composed of fortyone 4-mm thick, interleaved slices ( $0.5 \mathrm{~mm}$ interslice gap). For a subset of participants ( 8 in the ADHD group, 5 in the TD group), initial scanning parameters did not permit full coverage of the brain during EPI images; for these subjects, each volume was composed of thirty-four $4.5-\mathrm{mm}$ slices, and the posterior occipital lobe and a small region of the posterior aspect of the cerebellum were not captured.

\section{Postacquisition Processing}

Postacquisition image processing was carried out using MATLAB version 6.1 (The Mathworks, Inc.) and SPM2 (Wellcome Department of Imaging Neuroscience, www.fil.ion.ucl.ac.uk/spm/software/spm2).

\section{fMRI Data Preprocessing}

Functional DICOM images were converted to Analyze format. Due to susceptibility artifacts present in EPI acquisition, cost function masking was used to optimize normalization to the EPI template (Brett, Leff, Rorden, \& Ashburner, 2001). The functional volumes were timecorrected to adjust for within-volume time of acquisition differences (Calhoun, Adali, Kraut, \& Pearlson, 2000) and spatially realigned to the location of the first image in the time series. For each subject, a mean functional volume was created and coregistered to the subject's highresolution anatomical image in order to permit optimal identification of areas of susceptibility artifact. Masks were created by hand using MRIcro (www.sph.sc.edu/comd/rorden/mricro.html). Functional images were normalized to the MNI EPI template using a 12-parameter affine transformation and 16 nonlinear deformations. The functional images were then smoothed (Calhoun et al., 2000) using a Gaussian kernel of $6 \times$ $6 \times 6 \mathrm{~mm}$. 


\section{Head Motion Analysis}

Head movement was measured using the root mean square of the $x, y$, and $z$ realignment parameters for each subject as reported by SPM2 during spatial realignment. None of the subjects demonstrated greater than $3.5 \mathrm{~mm}$ of head movement in any direction, which is less than the size of one acquisition voxel $(3.59 \times 3.59 \times 4.5 \mathrm{~mm})$.

\section{fMRI Data Analysis}

SPM2 was used to construct and examine the fit of the image data to a general linear model (Friston et al., 1995) that specifically tested for and created statistical maps corresponding to the time course of correct go responses in contrast to baseline and correct no-go responses in contrast to baseline. Voxelwise $t$ maps were constructed for each participant as a first-level analysis. Activation in each voxel was contrasted with an implicit baseline of general task activation, which included null time between trials and the four 10-sec rest breaks but excluded activation linked to any of the five model regressors (go, no-go, commission error, omission error, and anticipatory "go" response occurring less than $200 \mathrm{msec}$ after stimulus presentation). The amplitude maps were then carried to a second-level analysis to test for significant group effects using Gaussian random field theory. The two-level strategy described is equivalent to a random effects analysis in that it provides a representative activation for a given population that is dominated by intersubject variance rather than interscan variance (Holmes \& Friston, 1998).

Single-group whole-brain random effects analyses were accomplished in SPM2 by executing one-sample $t$ tests on the individual subjects' go and no-go contrast images. Within-group contrasts (go vs. baseline and no-go vs. baseline) for ADHD and TD controls were performed at a voxel threshold of $p=.001$ and a cluster extent of 72 voxels, achieving a corrected statistical threshold of $p=.05$, determined by AlphaSim (B. D. Ward;

http://afni.nimh.nih.gov/afni/docpdf/ALPHASim.pdf), which was used to run 1000 Monte Carlo simulations which approximated random noise. Location of voxels significantly associated with go and no-go events were determined by summarizing local maxima separated by at least $8 \mathrm{~mm}$ and converting maxima from MNI to Talairach coordinate space using formulas provided by Matthew Brett (Medical Research Council-Cognition and Brain Sciences Unit; www.mrc-cbu.cam.ac.uk/Imaging/Common/mnispace.shtml). These coordinates were assigned neuroanatomic and cytoarchitectonic labels using the Talairach Daemon (Research Imaging Center, University of Texas Health Science Center at San Antonio; http://ric.uthscsa.edu/resources/body.html) and were reviewed by a neurologist (SHM).

Between-group contrasts were performed with region-of-interest (ROI) analyses using the MarsBaR ROI toolbox for SPM (http://marsbar.sourceforge.net) by comparing mean voxel values within the specified ROIs for the ADHD and TD groups. ROIs included all voxels activated in the TD or ADHD group at a voxel threshold of $p=.001$ and a cluster threshold of 72 ( $p=.05$, corrected for multiple comparisons) for the corresponding contrast (go or no-go). Clusters appearing in overlapping anatomic regions in the TD and ADHD groups (e.g., primary motor cortex in go contrasts) were combined into one ROI using the union of the clusters from the two groups. Bonferroni correction was made for the total number of ROIs examined across the go and no-go contrasts $(n=18)$, and corrected $p$ values are reported. In addition, exploratory whole-brain between-group analyses for go and no-go events were performed at the corrected threshold. 


\section{Results}

\section{Behavioral Results}

The absolute number of errors committed by the children with ADHD was greater than that of the TD children (Table 1); however, there was no significant difference in commission errors (failure to inhibit responding to "no-go" stimuli) between the ADHD and TD groups (mean \pm standard deviation $=24.7 \pm 14.1 \%$ vs. $22.0 \pm 11.5 \%$, respectively). Additionally, there was no significant difference between the groups in percentage of omission errors (failure to respond to "go" stimuli) $(4.2 \pm 4.4 \%$ vs. $2.8 \pm 3.8 \%)$ or response time for "go" stimuli $(445.4 \pm 118.2$ msec vs. $407.8 \pm 86.1 \mathrm{msec}$, the TD response time data is based upon 24 subjects, as one TD subject's response time data were not recorded due to mechanical error).

\section{fMRI Results}

Within-group Analyses-In within-group analyses, both groups of children showed gorelated activation in the left primary sensorimotor cortex (BA 3/4), left supplemental motor area ("SMA," BA6), right anterior superior cerebellum (culmen), left posterior superior cerebellum and thalamus, and bilateral occipital lobes (BA 19) (Figure 1). In addition, children with ADHD showed activation in the left parahippocampal gyrus (BA 35), right hippocampus, and right caudate, whereas TD children additionally showed activation in the left angular gyrus (BA 39).

In within-group analyses, both groups of children showed no-go-related activation in the bilateral rostral supplemental motor area ("pre-SMA"; BA 6), with the anterior inferior portion of the area of activation bordering on BA 32 (Figure 2 and Table 2). TD children additionally showed activation in bilateral occipital lobes (BA 18/19) and right middle frontal gyrus (BA 9/10), superior temporal gyrus (BA 22/42), anterior cerebellum (culmen), and putamen.

Between-group Analyses-For go events, there were a total of 11 ROIs examined for between-group differences. ROIs included the conjunction of clusters of activation in the TD and ADHD group corrected go maps in the left primary motor cortex, left SMA, right anterior cerebellum (culmen), left cerebellum, left occipital lobe, and left thalamus, as well as the clusters of go-related activation identified only on the TD (left angular gyrus, left precentral gyrus) or ADHD (right caudate, right hippocampus, left parahippocampal gyrus) group maps.

There was no significant difference in activation between the TD and ADHD groups in any ROI for go events (Figure 3, Table 3); additionally, in exploratory whole-brain between-group analysis, no differences were identified for go events at a corrected threshold.

For no-go events, seven ROIs were identified, including the conjunction of the TD and ADHD no-go-related pre-SMA clusters of activation, as well as the clusters of activation in the right cerebellar culmen, bilateral extrastriate visual cortex (BA 19), right temporal-parietal junction, right putamen, and right dorsolateral prefrontal cortex, identified from the TD group no-go contrast map.

There were no no-go ROIs in which the children with ADHD demonstrated greater activation than the TD children. As hypothesized, the TD group demonstrated significantly increased nogo-related activation in comparison to the ADHD group in the ROI in the pre-SMA (BA 6) $(t=3.36, p=.01)$ (Figure 4, Table 4$)$. The TD group additionally showed increased activation relative to the ADHD group within the right anterior cerebellum (culmen) $(t=3.25, p=.02)$, right temporal-parietal junction $(\mathrm{BA} 22 / 42)(t=4.01, p=.002)$, and bilateral extrastriate visual cortex (right: $t=3.53, p=.008$; left: $t=3.01, p=.04$ ). No significant between-group differences were identified in the ROIs in the right middle frontal gyrus (BA 9/10) and putamen. 
At the corrected threshold ( $p=.001$, uncorrected, voxel threshold $=72$, equivalent to $p=.05$ ), no between-group differences were identified for no-go events in exploratory whole-brain analyses. In order to further evaluate findings from ROI analysis for no-go events, a slightly more lenient threshold ( $p=.001$, uncorrected, voxel threshold $=5$ ) was used to examine wholebrain analyses for no-go related group differences. At the lower threshold, for the TD > ADHD no-go-related contrast, there was overlap with findings from ROI analyses, with TD children showing greater activation in the left pre-SMA (BA 6), right temporal-parietal junction, and bilateral extrastriate visual cortex (BA 19). Additionally, TD children showed greater no-gorelated activation in the left anterior cerebellum (culmen), anterior cingulate (BA 32), left fusiform gyrus (BA 37/19), and left primary sensorimotor cortex (BA 3/4) (Figure 5 and Table 5). In the ADHD > TD contrast, the children with ADHD demonstrated greater activation in the right primary sensorimotor cortex in comparison to the TD children (Figure 5 and Table $6)$.

\section{Discussion}

The neural mechanisms underlying habituated motor responding and motor response inhibition in children with ADHD were studied by comparing fMRI activation between children with and without ADHD performing a simplified go/no-go task. A well-ingrained stimulusresponse association (green $=$ go; red $=$ no-go) was used to minimize cognitive factors. By reducing the complexity of the task, we have lessened the potential confound of brain activation related to cognitive demands (such as that necessary to recall multiple unfamiliar stimulusresponse associations) other than response inhibition.

No between-group differences in activation were identified in relation to "Go" events. This task involves a single "Go" response, the push of one button, which becomes habituated by frequent repetition. Thus, for a habituated motor response, the children with ADHD showed no differences in neural activation compared to TD peers. In contrast, robust between-group differences in activation were identified in conjunction with no-go events, in which a switch in response (to inhibit responding) was required. Consistent with our hypothesis, within the frontal regions, between-group differences were limited to the pre-SMA, with the children with ADHD demonstrating reduced pre-SMA activation compared with the TD children; however, the children with ADHD additionally displayed reduced activation across a broader neural network important for response selection to a visual stimulus.

Similar to findings in adults performing this task (Mostofsky, Schafer, et al., 2003), results of within-group analyses of both children with ADHD and the TD controls revealed no-go-related activation of the bilateral medial frontal wall. In both groups, activation was principally localized to the pre-SMA. This is consistent with findings from lesion, imaging, and electrophysiological studies indicating the importance of the pre-SMA in motor response preparation and selection, including selecting to inhibit a motor response (Picton et al., 2006; Shibasaki \& Hallett, 2006; Mostofsky, Schafer, et al., 2003; Connolly et al., 2000; Toma et al., 1999). The pre-SMA is located rostral to the SMA proper and is distinct from the SMA in its anatomic connectivity. The pre-SMA is richly connected to the anterior prefrontal areas (Lu, Preston, \& Strick, 1994; Luppino, Matelli, Camarda, \& Rizzolatti, 1993), whereas the SMA proper demonstrates significant connections to the primary motor cortex and spinal cord (Luppino et al., 1993; Dum \& Strick, 1991). Furthermore, striatal projections from the preSMA largely extend to the caudate nucleus and middle and rostral putamen, whereas fibers from the SMA proper are predominantly associated with the caudal portion of the putamen (Lehericy et al., 2004). Functional roles appear to differentiate the SMA from the pre-SMA as well, with pre-SMA activation being associated with motor planning, readiness for action, and switching from automatic to volitionally controlled actions, whereas the SMA is activated for task execution (Isoda \& Hikosaka, 2007; Hoshi \& Tanji, 2004; Picard \& Strick, 1996). 
In ROI and exploratory whole-brain between-group contrasts, TD children demonstrated greater activation in the pre-SMA compared to children with ADHD. This finding suggests that there is dysfunction within the premotor system in children with ADHD. Suboptimal recruitment of the pre-SMA may be related to observable problems not only with motor inhibition but more broadly with switching of motor responses, which requires inhibition of a habitual response followed by facilitation of an alternative response (Isoda \& Hikosaka, 2007). The pre-SMA plays an important role in motor response preparation, deficits in which have been repeatedly demonstrated in children with ADHD, namely, with regard to slowed response preparation and increased intraindividual variability in response time (Toplak \& Tannock, 2005; Epstein et al., 2003; Mostofsky et al., 2001; Steger et al., 2001; Leth-Steensen, Elbaz, \& Douglas, 2000). Furthermore, these problems with response preparation are being increasingly emphasized in the literature as hallmarks of ADHD (Kuntsi, McLoughlin, \& Asherson, 2006; Castellanos et al., 2005; Klimkeit et al., 2005). Difficulties with motor response preparation appear to be part of a broader deficiency observed in children with ADHD, that of motor control, which is observed in parallel to abnormalities in cognitive and sociomotivational control. Clinically, multiple abnormalities of the motor system have been identified in children with ADHD, including persistence of overflow movements (Rubia, Taylor, Taylor, \& Sergeant, 1999; Denckla \& Rudel, 1978), impaired timing of motor responses (Rubia, Taylor, et al., 1999), and deficits in fine motor abilities (Pitcher, Piek, \& Hay, 2003). Anatomic imaging studies have provided additional support for abnormalities in the motor systems of children with ADHD, uncovering smaller premotor tissue volume (Mostofsky, Cooper, Kates, Denckla, \& Kaufmann, 2002), cortical thinning in the superior frontal wall consistent with the pre-SMA (Shaw et al., 2006), reversed asymmetry of putamen volume (Wellington, Semrud-Clikeman, Gregory, Murphy, \& Lancaster, 2006), and smaller posterior inferior cerebellar vermis volume (Castellanos et al., 2001; Berquin et al., 1998; Mostofsky, Reiss, Lockhart, \& Denckla, 1998).

In addition to the pre-SMA, ROI and whole-brain analyses revealed decreased no-go-related activation by the children with ADHD in additional structures involved in neural networks important for switching behavior, including inhibiting a habituated response. These areas included the anterior cerebellum, the extrastriate visual cortex (BA 19), and the right temporalparietal junction. The anterior cerebellum is part of a circuit that includes the pre-SMA (Middleton \& Strick, 1997) and appears to be important for response inhibition, whereas the extrastriate visual cortex is important for visual processing of stimuli. Lastly, the right temporal-parietal junction has been previously identified as playing an important role in response inhibition with regard to identifying the behavioral relevance of stimuli and enabling a variety of responses to salient stimuli (Astafiev, Shulman, \& Corbetta, 2006; Downar, Crawley, Mikulis, \& Davis, 2002). As we did not identify any regions in which the children with ADHD demonstrated greater no-go-related activation than did TD children, our findings do not suggest a compensatory mechanism by which the children with ADHD achieved statistically equivalent task accuracy despite lesser activation of neural networks important for switching behavior.

Our findings are consistent with prior go/no-go studies of response inhibition in children with ADHD identifying reduced activation in the pre-SMA and premotor cortex. With a task using a 3:1 go/no-go ratio and three letters representing three possible motor responses, Tamm et al. (2004) localized greater activation in their control group to the anterior cingulate with overlap with the pre-SMA. Durston et al. (2006) demonstrated decreased activation in the left premotor cortex in children with ADHD, also using a 3:1 go/no-go ratio and incorporating multiple cartoon characters as stimuli in a task with two motor possible motor responses.

Beyond the pre-SMA, we did not identify additional frontal areas that were differentially activated by children with ADHD and TD children. Several regions of the right prefrontal 
cortex, more specifically the inferior frontal cortex and the dorsolateral prefrontal cortex, have been previously identified as playing an important role in response inhibition in typical children and adults (Blasi et al., 2006; Aron et al., 2004; Asahi, Okamoto, Okada, Yamawaki, \& Yokota, 2004). Our analyses revealed no-go-related activation for the TD group in the right dorsolateral prefrontal cortex, although no between-group differences were seen in this area or in the region of the inferior frontal cortex. Between-group differences for no-go-related activation in right prefrontal regions in ADHD has been inconsistent, as both increased and decreased right prefrontal activation have been reported in event-related fMRI studies of children with ADHD performing tasks of response inhibition. Across differing regions or cohorts, both increased and decreased right prefrontal activation have been reported in go/no-go tasks with many stimuli and two possible responses (Durston et al., 2003, 2006; Schulz et al., 2004). Decreased right prefrontal activation has additionally been shown in studies using go/no-go and stopsignal tasks with three possible responses (Pliszka et al., 2006; Rubia et al., 2005; Tamm et al., 2004). It has been suggested that prefrontal regions are recruited to guide response inhibition depending on the demands of the task; in a study of healthy adults, when a cognitive demand was added to a simplified go/no-go task similar to the one used in the present study, activation was seen in the dorsolateral prefrontal cortex in addition to the pre-SMA (Mostofsky, Schafer, et al., 2003). Group differences in right prefrontal activation identified in prior ADHD studies may have resulted from varying task demands (such as the need to recall multiple newly learned stimulus-response associations), and our go/no-go task may have reduced cognitive demands sufficiently such that differential recruitment of these prefrontal regions was not observed between the ADHD and TD groups.

Given that we found group differences in the frontal region localized to the pre-SMA, a possible explanation is that abnormality in pre-SMA circuits is central to impaired response inhibition in ADHD regardless of task demand. If this were the case, one might expect to find differences in pre-SMA activation more consistently across fMRI studies in ADHD. Alternatively, abnormalities in additional prefrontal circuits may contribute to impaired response inhibition in more complex contexts involving control of cognitive and socioemotional function, explaining the variation in regions of prefrontal activation identified across studies. These competing hypotheses could be examined in ADHD using an fMRI experimental design previously applied to adults (Mostofsky, Schafer, et al., 2003), in which response inhibition is examined using two different go/no-go paradigms with distinct task demands.

Relative hypoactivation of the pre-SMA by children with ADHD in association with inhibition of a motor response could be due to (a) reduced number of neurons and/or dendritic connections within the pre-SMA, (b) reduced functional activation of the available neurons, or (c) a combination of anatomic and functional deficits in comparison to TD children. Cerebral cortical gray matter abnormalities have been reported in children with ADHD, with reports of global decrease in gray matter volume (Carmona et al., 2005) and cortical thinning (Shaw et al., 2006), as well as localized anomalies in the region of the pre-SMA, including reduced volume (Carmona et al., 2005; Mostofsky et al., 2002) and thickness as compared with control children (Shaw et al., 2006). These anomalies of cortical volume and thickness provide support for an anatomic contribution to the observed relative hypoactivation of the pre-SMA. Future analyses using gray matter composition as a covariate for BOLD activation may help elucidate the relative anatomic versus functional deficits to the observed hypoactivation in the pre-SMA, as well as to the relative hypoactivation observed on a more global scale, as can be observed in the comparison of the ADHD and TD group contrasts for go and no-go associated activation (Figures 1 and 2).

The absence of differences in activation for the go motor response is somewhat surprising, given that dysfunction of the motor system in ADHD has been previously demonstrated in an fMRI study of finger sequencing in which children with ADHD showed less effective 
recruitment of the primary motor cortex compared with their typically developing peers (Mostofsky et al., 2006). However, the finger sequencing task, requiring sequential touching of the four fingers to the thumb, represents a more complicated, nonhabituated task, as compared to the simple, habituated go motor response. In the present study, the lack of differences in pre-SMA activation during go responses may be due to lesser motor planning and preparation demands associated with the repeated, automatic "go" action as opposed to the infrequent demand to change motor behavior to inhibit responding to no-go stimuli.

The children with ADHD achieved nearly the behavioral accuracy of the TD controls on the behavioral task, with no significant difference between groups in accuracy on the go/no-go task. Statistically equivalent task accuracy both minimizes the likelihood that group differences in activation are due to differences in task difficulty for the two groups of children and equalizes statistical power for group analyses. However, in general, children with ADHD are known to demonstrate deficits on tasks of response inhibition compared to their peers without ADHD (Mahone et al., 2006; Klimkeit et al., 2005; Schachar, Tannock, Marriott, \& Logan, 1995). The current cohort of children with ADHD did demonstrate a greater number of commission and omission errors; however, these differences were not statistically different. True diagnosesbased group differences in activation associated with response inhibition may have been diluted due to exclusion of children with ADHD who were unable to meet movement and performance criteria. Furthermore, intraindividual variability is an additional parameter of task performance with particular relevance to children with ADHD (Klein et al., 2006), which was not examined in the context of this work but may provide additional information regarding differences in the neural mechanisms of response inhibition in ADHD. A technical limitation of this study is the exclusion of portions of occipital lobes and a small region of the posterior cerebellum from data analyses, necessitated by initial scanning parameters that did not allow for capture of the full brain.

In conclusion, under conditions in which the cognitive demands needed to guide response selection were minimized, for habitual motor responding, no differences in neural activation were observed between children with ADHD and TD children. In contrast, when required to withhold from responding, children with ADHD showed diminished recruitment in networks that are important for response selection, with frontal differences localized to the pre-SMA. These findings lend support to the growing awareness of ADHD-associated anomalies in medial frontal regions important for the control of voluntary actions. Further analyses may elucidate whether hypoactivation of the pre-SMA is due to decreased neuronal capacity within the pre-SMA and/or a lesser degree of functional activation within the pre-SMA as compared to TD children and may additionally determine the relationship between intraindividual variability and prefrontal activation in children with ADHD. Further investigation is also needed to determine whether additional differential activation is observed in prefrontal circuits during performance of tasks in which increased cognitive/behavioral (e.g., working memory) processing is necessary to guide response inhibition.

\section{References}

Aron AR, Robbins TW, Poldrack RA. Inhibition and the right inferior frontal cortex. Trends in Cognitive Sciences 2004;8:170-177. [PubMed: 15050513]

Asahi S, Okamoto Y, Okada G, Yamawaki S, Yokota N. Negative correlation between right prefrontal activity during response inhibition and impulsiveness: A fMRI study. European Archives of Psychiatry and Clinical Neuroscience 2004;254:245-251. [PubMed: 15309395]

Astafiev SV, Shulman GL, Corbetta M. Visuospatial reorienting signals in the human temporo-parietal junction are independent of response selection. European Journal of Neuroscience 2006;23:591-596. [PubMed: 16420468] 
Barkley RA. Behavioral inhibition, sustained attention, and executive functions: Constructing a unifying theory of ADHD. Psychological Bulletin 1997;121:65-94. [PubMed: 9000892]

Bellgrove MA, Hester R, Garavan H. The functional neuroanatomical correlates of response variability: Evidence from a response inhibition task. Neuropsychologia 2004;42:1910-1916. [PubMed: 15381021]

Berlin L, Bohlin G, Nyberg L, Janols LO. How well do measures of inhibition and other executive functions discriminate between children with ADHD and controls? Child Neuropsychology 2004;10:1-13. [PubMed: 14977511]

Berquin PC, Giedd JN, Jacobsen LK, Hamburger SD, Krain AL, Rapoport JL, et al. Cerebellum in attention-deficit hyperactivity disorder: A morphometric MRI study. Neurology 1998;50:1087-1093. [PubMed: 9566399]

Blasi G, Goldberg TE, Weickert T, Das S, Kohn P, Zoltick B, et al. Brain regions underlying response inhibition and interference monitoring and suppression. European Journal of Neuroscience 2006;23:1658-1664. [PubMed: 16553630]

Booth JR, Burman DD, Meyer JR, Lei Z, Trommer BL, Davenport ND, et al. Neural development of selective attention and response inhibition. Neuroimage 2003;20:737-751. [PubMed: 14568448]

Booth JR, Burman DD, Meyer JR, Lei Z, Trommer BL, Davenport ND, et al. Larger deficits in brain networks for response inhibition than for visual selective attention in attention deficit hyperactivity disorder (ADHD). Journal of Child Psychology and Psychiatry 2005;46:94-111. [PubMed: 15660647]

Booth JR, Burman DD, Meyer JR, Trommer BL, Davenport ND, Parrish TB, et al. Brain-behavior correlation in children depends on the neurocognitive network. Human Brain Mapping 2004;23:99108. [PubMed: 15340932]

Brett M, Leff AP, Rorden C, Ashburner J. Spatial normalization of brain images with focal lesions using cost function masking. Neuroimage 2001;14:486-500. [PubMed: 11467921]

Calhoun V, Adali T, Kraut M, Pearlson G. A weighted least-squares algorithm for estimation and visualization of relative latencies in event-related functional MRI. Magnetic Resonance in Medicine 2000;44:947-954. [PubMed: 11108633]

Carmona S, Vilarroya O, Bielsa A, Tremols V, Soliva JC, Rovira M, et al. Global and regional gray matter reductions in ADHD: A voxel-based morphometric study. Neuroscience Letters 2005;389:8893. [PubMed: 16129560]

Castellanos FX, Giedd JN, Berquin PC, Walter JM, Sharp W, Tran T, et al. Quantitative brain magnetic resonance imaging in girls with attention-deficit/hyperactivity disorder. Archives of General Psychiatry 2001;58:289-295. [PubMed: 11231836]

Castellanos FX, Sonuga-Barke EJ, Scheres A, Di Martino A, Hyde C, Walters JR. Varieties of attentiondeficit/hyperactivity disorder-related intra-individual variability. Biological Psychiatry 2005;57:1416-1423. [PubMed: 15950016]

Conners, CK. Conners Rating Scales—revised. North Tonawanda, NY: Multiheath Systems; 1997.

Connolly JD, Goodale MA, Desouza JF, Menon RS, Vilis T. A comparison of frontoparietal fMRI activation during anti-saccades and anti-pointing. Journal of Neurophysiology 2000;84:1645-1655. [PubMed: 10980034]

Denckla MB, Rudel RG. Anomalies of motor development in hyperactive boys. Annals of Neurology 1978;3:231-233. [PubMed: 666263]

Downar J, Crawley AP, Mikulis DJ, Davis KD. A cortical network sensitive to stimulus salience in a neutral behavioral context across multiple sensory modalities. Journal of Neurophysiology 2002;87:615-620. [PubMed: 11784775]

Dum RP, Strick PL. The origin of corticospinal projections from the premotor areas in the frontal lobe. Journal of Neuroscience 1991;11:667-689. [PubMed: 1705965]

Durston S, Mulder M, Casey BJ, Ziermans T, van Engeland H. Activation in ventral prefrontal cortex is sensitive to genetic vulnerability for attention-deficit hyperactivity disorder. Biological Psychiatry 2006;60:1062-1070. [PubMed: 16712804]

Durston S, Tottenham NT, Thomas KM, Davidson MC, Eigsti IM, Yang YH, et al. Differential patterns of striatal activation in young children with and without ADHD. Biological Psychiatry 2003;53:871878. [PubMed: 12742674] 
Epstein JN, Erkanli A, Conners CK, Klaric J, Costello JE, Angold A. Relations between Continuous Performance Test performance measures and ADHD behaviors. Journal of Abnormal Child Psychology 2003;31:543-554. [PubMed: 14561061]

Feifel D, Farber RH, Clementz BA, Perry W, Anllo-Vento L. Inhibitory deficits in ocular motor behavior in adults with attention-deficit/hyperactivity disorder. Biological Psychiatry 2004;56:333-339. [PubMed: 15336515]

Floden D, Stuss DT. Inhibitory control is slowed in patients with right superior medial frontal damage. Journal of Cognitive Neuroscience 2006;18:1843-1849. [PubMed: 17069475]

Friston KJ, Holmes AP, Worsley KJ, Poline JP, Frith CD, Frackowiak RSJ. Statistical parametric maps in functional imaging: A general linear approach. Human Brain Mapping 1995;2:189-210.

Garavan H, Hester R, Murphy K, Fassbender C, Kelly C. Individual differences in the functional neuroanatomy of inhibitory control. Brain Research 2006;1105:130-142. [PubMed: 16650836]

Garavan H, Ross TJ, Stein EA. Right hemispheric dominance of inhibitory control: An event-related functional MRI study. Proceedings of the National Academy of Sciences, USA 1999;96:8301-8306.

Goldberg MC, Mostofsky SH, Cutting LE, Mahone EM, Astor BC, Denckla MB, et al. Subtle executive impairment in children with autism and children with ADHD. Journal of Autism and Developmental Disorders 2005;35:279-293. [PubMed: 16119469]

Hanisch C, Radach R, Holtkamp K, Herpertz-Dahlmann B, Konrad K. Oculomotor inhibition in children with and without attention-deficit hyperactivity disorder (ADHD). Journal of Neural Transmission 2006;113:671-684. [PubMed: 16082513]

Hester RL, Murphy K, Foxe JJ, Foxe DM, Javitt DC, Garavan H. Predicting success: Patterns of cortical activation and deactivation prior to response inhibition. Journal of Cognitive Neuroscience 2004;16:776-785. [PubMed: 15200705]

Holmes AP, Friston KJ. Generalisability, random effects and population inference. Neuroimage 1998;7:S754.

Hoshi E, Tanji J. Differential roles of neuronal activity in the supplementary and presupplementary motor areas: From information retrieval to motor planning and execution. Journal of Neurophysiology 2004;92:3482-3499. [PubMed: 15269227]

Humberstone M, Sawle GV, Clare S, Hykin J, Coxon R, Bowtell R, et al. Functional magnetic resonance imaging of single motor events reveals human presupplementary motor area. Annals of Neurology 1997;42:632-637. [PubMed: 9382475]

Hurks PP, Adam JJ, Hendriksen JG, Vles JS, Feron FJ, Kalff AC, et al. Controlled visuomotor preparation deficits in attention-deficit/hyperactivity disorder. Neuropsychology 2005;19:66-76. [PubMed: 15656764]

Isoda M, Hikosaka O. Switching from automatic to controlled action by monkey medial frontal cortex. Nature Neuroscience 2007;10:240-248.

Klein C, Wendling K, Huettner P, Ruder H, Peper M. Intra-subject variability in attention-deficit hyperactivity disorder. Biological Psychiatry 2006;60:1088-1097. [PubMed: 16806097]

Klimkeit EI, Mattingley JB, Sheppard DM, Lee P, Bradshaw JL. Motor preparation, motor execution, attention, and executive functions in attention deficit/hyperactivity disorder (ADHD). Child Neuropsychology 2005;11:153-173. [PubMed: 16036442]

Konishi S, Nakajima K, Uchida I, Kikyo H, Kameyama M, Miyashita Y. Common inhibitory mechanism in human inferior prefrontal cortex revealed by event-related functional MRI. Brain 1999;122:981991. [PubMed: 10355680]

Kuntsi J, McLoughlin G, Asherson P. Attention deficit hyperactivity disorder. Neuromolecular Medicine 2006;8:461-484. [PubMed: 17028370]

Lehericy S, Ducros M, Krainik A, Francois C, Van de Moortele PF, Ugurbil K, et al. 3-D diffusion tensor axonal tracking shows distinct SMA and pre-SMA projections to the human striatum. Cerebral Cortex 2004;14:1302-1309. [PubMed: 15166103]

Leth-Steensen C, Elbaz ZK, Douglas VI. Mean response times, variability, and skew in the responding of ADHD children: A response time distributional approach. Acta Psychologica (Amsterdam) 2000;104:167-190. 
Lijffijt M, Kenemans JL, Verbaten MN, van Engeland H. A meta-analytic review of stopping performance in attention-deficit/hyperactivity disorder: Deficient inhibitory motor control? Journal of Abnormal Psychology 2005;114:216-222. [PubMed: 15869352]

Lu MT, Preston JB, Strick PL. Interconnections between the prefrontal cortex and the premotor areas in the frontal lobe. Journal of Comparative Neurology 1994;341:375-392. [PubMed: 7515081]

Luppino G, Matelli M, Camarda R, Rizzolatti G. Corticocortical connections of area F3 (SMA-proper) and area F6 (pre-SMA) in the macaque monkey. Journal of Comparative Neurology 1993;338:114140. [PubMed: 7507940]

Mahone EM, Koth CW, Cutting L, Singer HS, Denckla MB. Executive function in fluency and recall measures among children with Tourette syndrome or ADHD. Journal of the International Neuropsychological Society 2001;7:102-111. [PubMed: 11253836]

Mahone EM, Powell SK, Loftis CW, Goldberg MC, Denckla MB, Mostofsky SH. Motor persistence and inhibition in autism and ADHD. Journal of the International Neuropsychological Society 2006;12:622-631. [PubMed: 16961943]

Matsuzaka Y, Aizawa H, Tanji J. A motor areas rostral to the supplementary motor areas (presupplementary motor areas) in the monkey: Neuronal activity during a learned motor task. Journal of Neurophysiology 1992;68:653-662. [PubMed: 1432040]

Middleton, FA.; Strick, PL. Cerebellar output channels. In: Schmahmann, JD., editor. The cerebellum in cognition. San Diego: Academic Press; 1997. p. 61-107.

Mostofsky SH, Cooper KL, Kates WR, Denckla MB, Kaufmann WE. Smaller prefrontal and premotor volumes in boys with attention-deficit/hyperactivity disorder. Biological Psychiatry 2002;52:785794. [PubMed: 12372650]

Mostofsky SH, Lasker AG, Cutting LE, Denckla MB, Zee DS. Oculomotor abnormalities in attention deficit hyperactivity disorder: A preliminary study. Neurology 2001;57:423-430. [PubMed: 11502907]

Mostofsky SH, Newschaffer CJ, Denckla MB. Overflow movements predict impaired response inhibition in children with ADHD. Perceptual and Motor Skills 2003;97:1315-1331. [PubMed: 15002876]

Mostofsky SH, Reiss AL, Lockhart P, Denckla MB. Evaluation of cerebellar size in attention-deficit hyperactivity disorder. Journal of Child Neurology 1998;13:434-439. [PubMed: 9733289]

Mostofsky SH, Rimrodt SL, Schafer JG, Boyce A, Goldberg MC, Pekar JJ, et al. Atypical motor and sensory cortex activation in attention-deficit/hyperactivity disorder: A functional magnetic resonance imaging study of simple sequential finger tapping. Biological Psychiatry 2006;59:48-56. [PubMed: 16139806]

Mostofsky SH, Schafer JG, Abrams MT, Goldberg MC, Flower AA, Boyce A, et al. fMRI evidence that the neural basis of response inhibition is task-dependent. Brain Research, Cognitive Brain Research 2003;17:419-430. [PubMed: 12880912]

Nigg JT. The ADHD response-inhibition deficit as measured by the stop task: Replication with DSM-IV combined type, extension, and qualification. Journal of Abnormal Child Psychology 1999;27:393402. [PubMed: 10582840]

Nigg JT. Is ADHD a disinhibitory disorder? Psychological Bulletin 2001;127:571-598. [PubMed: 11548968]

Overtoom CC, Kenemans JL, Verbaten MN, Kemner C, van der Molen MW, van Engeland H, et al. Inhibition in children with attention-deficit/hyperactivity disorder: A psychophysiological study of the stop task. Biological Psychiatry 2002;51:668-676. [PubMed: 11955467]

Picard N, Strick PL. Motor areas of the medial wall: A review of their location and functional activation. Cerebral Cortex 1996;6:342-353. [PubMed: 8670662]

Picton TW, Stuss DT, Alexander MP, Shallice T, Binns MA, Gillingham S. Effects of focal frontal lesions on response inhibition. Cerebral Cortex 2006;17:826-838. [PubMed: 16699079]

Pitcher TM, Piek JP, Hay DA. Fine and gross motor ability in males with ADHD. Developmental Medicine and Child Neurology 2003;45:525-535. [PubMed: 12882531]

Pliszka SR, Glahn DC, Semrud-Clikeman M, Franklin C, Perez R III, Xiong J, et al. Neuroimaging of inhibitory control areas in children with attention deficit hyperactivity disorder who were treatment naive or in long-term treatment. American Journal of Psychiatry 2006;163:1052-1060. [PubMed: 16741206] 
Reader MJ, Harris EL, Scheuerholz LJ, Denckla MB. Attention deficit hyperactivity disorder and executive dysfunction. Developmental Neuropsychology 1994;10:493-512.

Reich W. Diagnostic interview for children and adolescents (DICA). Journal of the American Academy of Child and Adolescent Psychiatry 2000;39:59-66. [PubMed: 10638068]

Rubia K, Overmeyer S, Taylor E, Brammer M, Williams SCR, Simmons A, et al. Hypofrontality in attention deficit hyperactivity disorder during higher-order motor control: A study with functional MRI. American Journal of Psychiatry 1999;156:891-896. [PubMed: 10360128]

Rubia K, Russell T, Overmeyer S, Brammer MJ, Bullmore ET, Sharma T, et al. Mapping motor inhibition: Conjunctive brain activations across different versions of go/no-go and stop tasks. Neuroimage 2001;13:250-261. [PubMed: 11162266]

Rubia K, Smith AB, Brammer MJ, Toone B, Taylor E. Abnormal brain activation during inhibition and error detection in medication-naive adolescents with ADHD. American Journal of Psychiatry 2005;162:1067-1075. [PubMed: 15930054]

Rubia K, Smith AB, Woolley J, Nosarti C, Heyman I, Taylor E, et al. Progressive increase of frontostriatal brain activation from childhood to adulthood during event-related tasks of cognitive control. Human Brain Mapping 2006;27:973-993. [PubMed: 16683265]

Rubia K, Taylor A, Taylor E, Sergeant JA. Synchronization, anticipation, and consistency in motor timing of children with dimensionally defined attention deficit hyperactivity behavior. Perceptual and Motor Skills 1999;89:1237-1258. [PubMed: 10710774]

Schachar R, Tannock R, Marriott M, Logan G. Deficient inhibitory control in attention deficit hyperactivity disorder. Journal of Abnormal Child Psychology 1995;23:411-437. [PubMed: 7560554]

Schlaggar BL, Brown TT, Lugar HM, Visscher KM, Miezin FM, Petersen SE. Functional neuroanatomical differences between adults and school-age children in the processing of single words. Science 2002;296:1476-1479. [PubMed: 12029136]

Schulz KP, Fan J, Tang CY, Newcorn JH, Buchsbaum MS, Cheung AM, et al. Response inhibition in adolescents diagnosed with attention deficit hyperactivity disorder during childhood: An eventrelated fMRI study. American Journal of Psychiatry 2004;161:1650-1657. [PubMed: 15337656]

Shaw P, Lerch J, Greenstein D, Sharp W, Clasen L, Evans A, et al. Longitudinal mapping of cortical thickness and clinical outcome in children and adolescents with attention-deficit/hyperactivity disorder. Archives of General Psychiatry 2006;63:540-549. [PubMed: 16651511]

Shibasaki H, Hallett M. What is the Bereitschaftspotential? Clinical Neurophysiology 2006;117:23412356. [PubMed: 16876476]

Simmonds DJ, Fotedar SG, Suskauer SJ, Pekar JJ, Denckla MB, Mostofsky SH. Functional brain correlates of response time variability in children. Neuropsychologia 2007;45:2147-2157. [PubMed: 17350054]

Smith AB, Taylor E, Brammer M, Toone B, Rubia K. Task-specific hypoactivation in prefrontal and temporoparietal brain regions during motor inhibition and task switching in medication-naive children and adolescents with attention deficit hyperactivity disorder. American Journal of Psychiatry 2006;163:1044-1051. [PubMed: 16741205]

Steger J, Imhof K, Coutts E, Gundelfinger R, Steinhausen HC, Brandeis D. Attentional and neuromotor deficits in ADHD. Developmental Medicine and Child Neurology 2001;43:172-179. [PubMed: 11263687]

Stevens J, Quittner AL, Zuckerman JB, Moore S. Behavioral inhibition, self-regulation of motivation, and working memory in children with attention deficit hyperactivity disorder. Developmental Neuropsychology 2002;21:117-139. [PubMed: 12139195]

Tamm L, Menon V, Reiss AL. Parietal attentional system aberrations during target detection in adolescents with attention deficit hyperactivity disorder: Event-related fMRI evidence. American Journal of Psychiatry 2006;163:1033-1043. [PubMed: 16741204]

Tamm L, Menon V, Ringel J, Reiss AL. Event-related fMRI evidence of frontotemporal involvement in aberrant response inhibition and task switching in attention-deficit/hyperactivity disorder. Journal of the American Academy of Child and Adolescent Psychiatry 2004;43:1430-1440. [PubMed: 15502603] 
Toma K, Honda M, Hanakawa T, Okada T, Fukuyama H, Ikeda A, et al. Activities of the primary and supplementary motor areas increase in preparation and execution of voluntary muscle relaxation: An event-related fMRI study. Journal of Neuroscience 1999;19:3527-3534. [PubMed: 10212312]

Toplak ME, Tannock R. Tapping and anticipation performance in attention deficit hyperactivity disorder. Perceptual and Motor Skills 2005;100:659-675. [PubMed: 16060425]

Vaidya CJ, Bunge SA, Dudukovic NM, Zalecki CA, Elliott GR, Gabrieli JD. Altered neural substrates of cognitive control in childhood ADHD: Evidence from functional magnetic resonance imaging. American Journal of Psychiatry 2005;162:1605-1613. [PubMed: 16135618]

Verte S, Geurts HM, Roeyers H, Oosterlaan J, Sergeant JA. The relationship of working memory, inhibition, and response variability in child psychopathology. Journal of Neuroscience Methods 2006;151:5-14. [PubMed: 16427129]

Wager TD, Sylvester CY, Lacey SC, Nee DE, Franklin M, Jonides J. Common and unique components of response inhibition revealed by fMRI. Neuroimage 2005;27:323-340. [PubMed: 16019232]

Walcott CM, Landau S. The relation between disinhibition and emotion regulation in boys with attention deficit hyperactivity disorder. Journal of Clinical Child and Adolescent Psychology 2004;33:772782. [PubMed: 15498744]

Wechsler, DL. Wechsler Intelligence Scale for Children-III. San Antonio, TX: The Psychological Corporation; 1991.

Wechsler, DL. Wechsler Individual Achievement Test. San Antonio, TX: The Psychological Corporation; 1992.

Wechsler, DL. Weschsler Individual Achievement Test-II. San Antonio, TX: The Psychological Corporation; 2002.

Wechsler, DL. Wechsler Intelligence Scale for Children-IV. San Antonio, TX: The Psychological Corporation; 2003.

Wellington TM, Semrud-Clikeman M, Gregory AL, Murphy JM, Lancaster JL. Magnetic resonance imaging volumetric analysis of the putamen in children with ADHD: Combined type versus control. Journal of Attention Disorders 2006;10:171-180. [PubMed: 17085627] 
A

\section{Within-group contrasts for go-related activation}
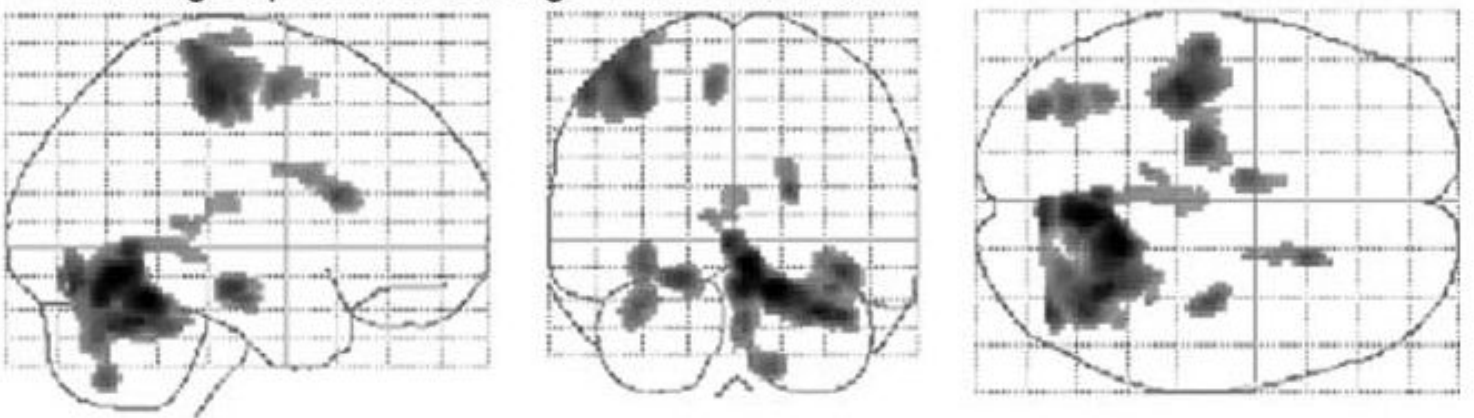

B
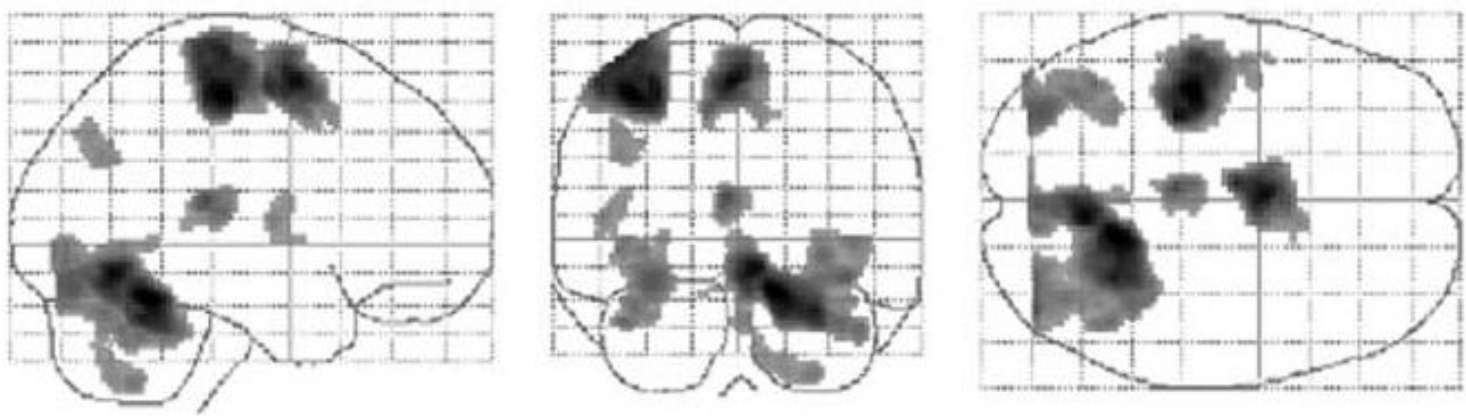

Figure 1.

Effects for go events within the (A) ADHD group and (B) TD controls. Transparent brain maps showing regions where the time courses were significant covariates of fMRI signal changes for go trials. These results are based on a random effects analysis of 25 subjects per group using an uncorrected threshold $p=.001$ and a cluster size threshold of 72 (equivalent to a corrected threshold $p=.05$ ). Neurologic convention is used (i.e., right = right hemisphere; projections looking rightward or into the page). For both groups, main effects of go are visible in the left primary sensorimotor cortex (BA 3/4), left supplementary motor area ("SMA," BA 6), right anterior superior cerebellum (culmen), left posterior superior cerebellum, and bilateral occipital lobes (BA 19). In the ADHD group, additional effects are seen in the left parahippocampal gyrus (BA 35), right hippocampus, and right caudate; in the TD group, additional effects are seen in the left angular gyrus (BA 39). 


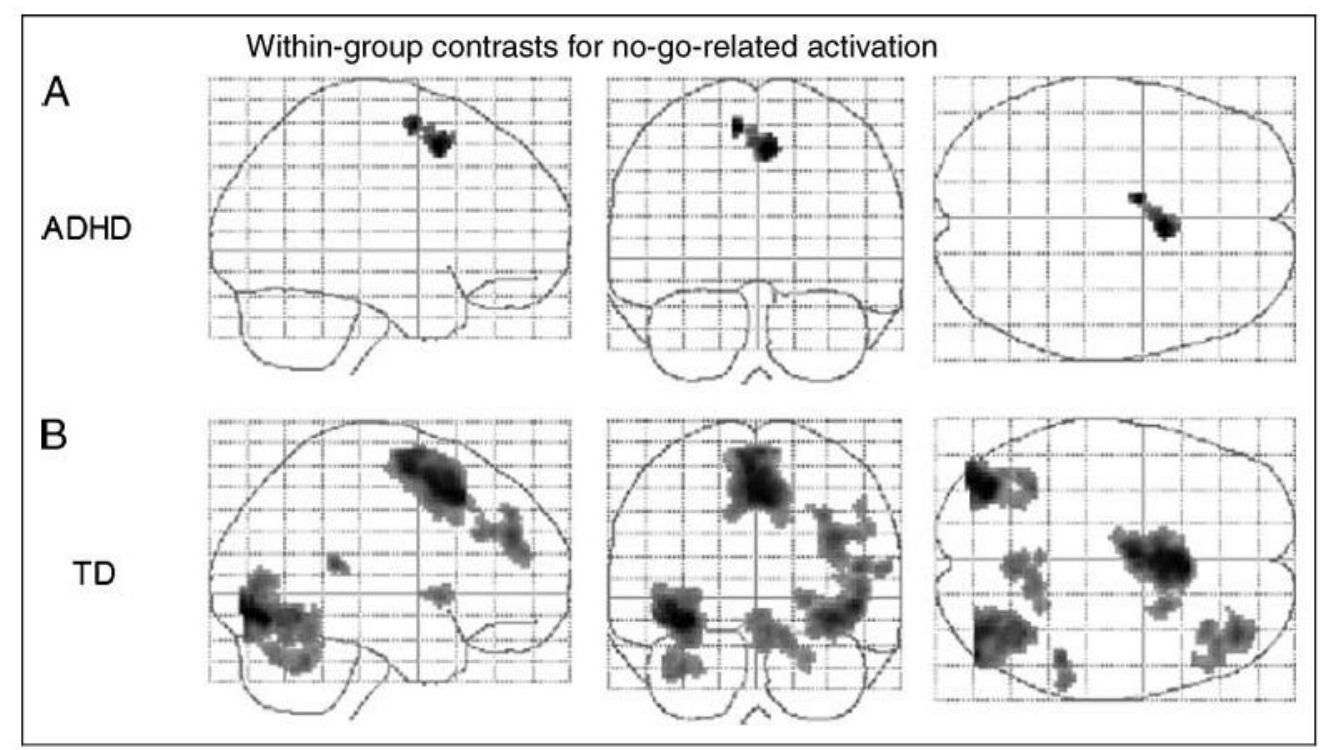

Figure 2.

Effects for no-go events within the (A) ADHD group and (B) TD controls. Transparent brain maps showing regions where the time courses were significant covariates of fMRI signal changes for no-go trials. These results are based on a random effects analysis of 25 subjects per group using an uncorrected threshold $p=.001$ and a cluster size threshold of 72 (equivalent to a corrected threshold $p=.05$ ). Neurologic convention is used (i.e., right = right hemisphere; projections looking rightward or into the page). For both groups, main effects of no-go are visible in the rostral supplementary motor area ("pre-SMA," BA 6). In the TD group, additional effects are seen in the bilateral occipital lobes, right middle frontal gyrus, superior temporal gyrus, cerebellar culmen, and putamen. 


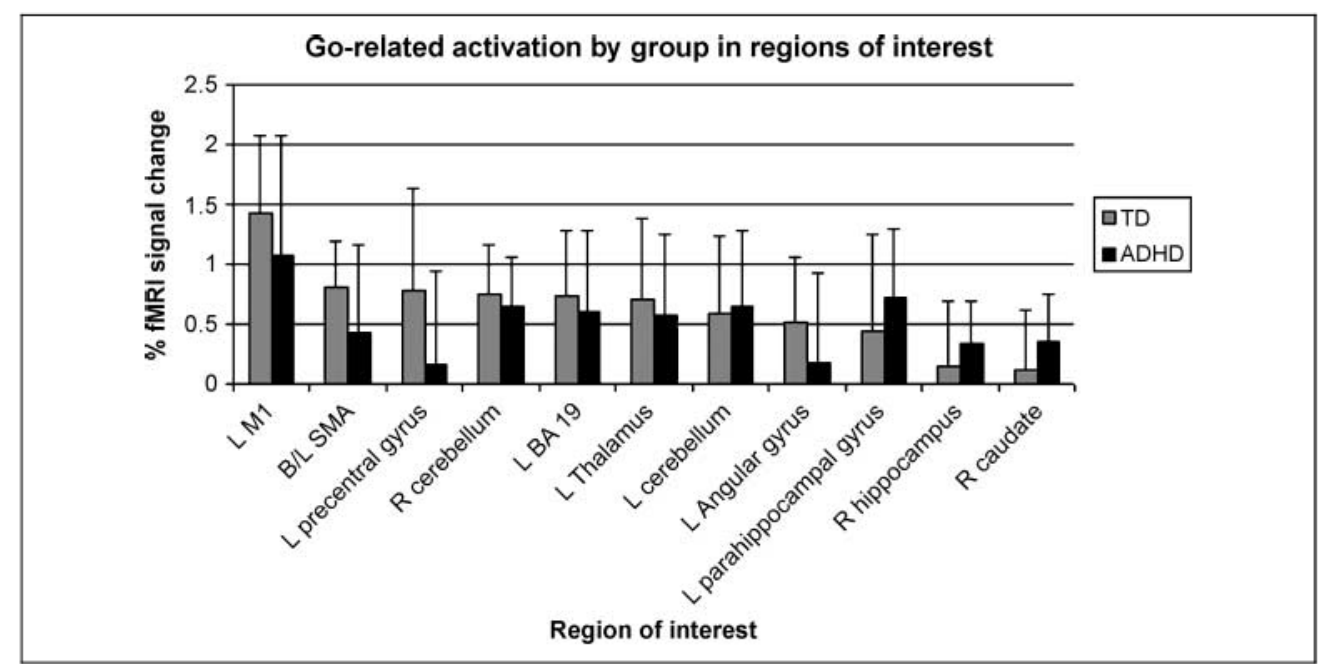

Figure 3.

Percentage of fMRI signal change for the TD children and children with ADHD in association with correct "go" responses in each ROI selected from TD and ADHD group "go" contrast maps. There were no significant differences between groups for go-related activation in any ROI ( $p<.05$, after Bonferroni correction for multiple comparisons). M1 = primary motor cortex. 


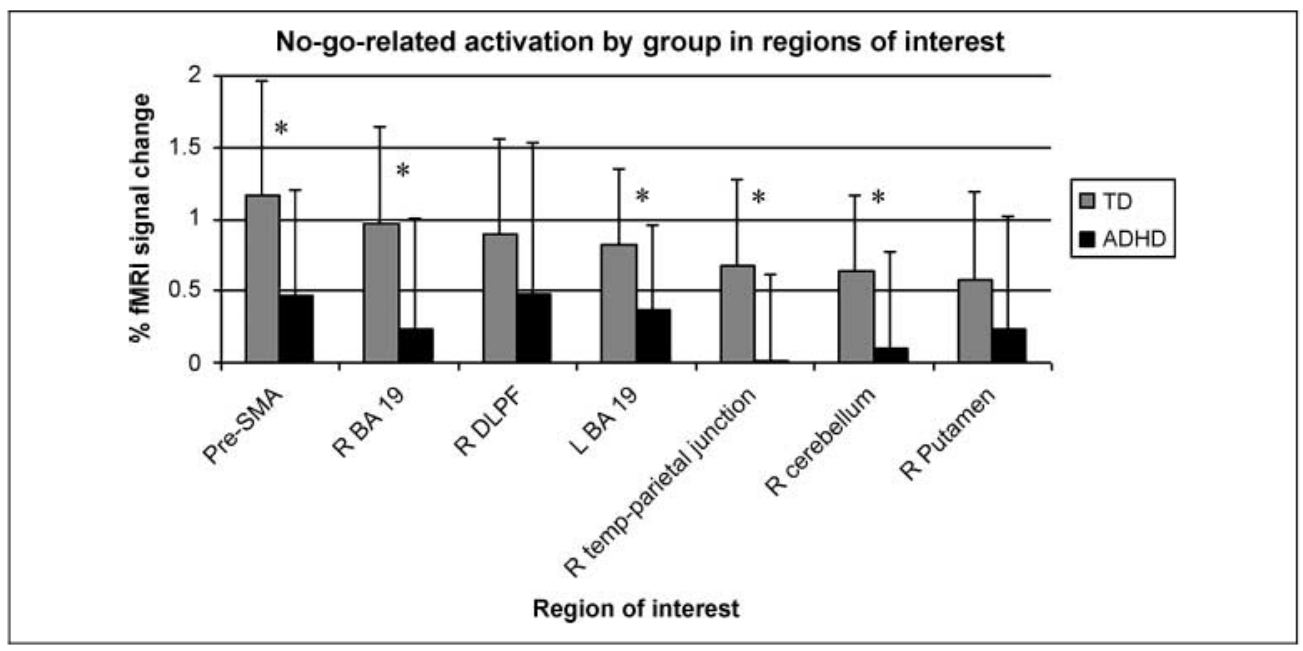

Figure 4.

Percentage of fMRI signal change for the TD children and children with ADHD in association with correct "no-go" responses in each ROI selected from TD and ADHD group "no-go" contrast maps. ROIs with significant between-group differences $(p<.05$, after Bonferroni correction for multiple comparisons) are noted with an *. The TD children had significantly greater activation than the ADHD group in the pre-SMA, right cerebellum, bilateral occipital lobes (BA 19), and right temporal-parietal junction. 
A
TD $>$ ADHD

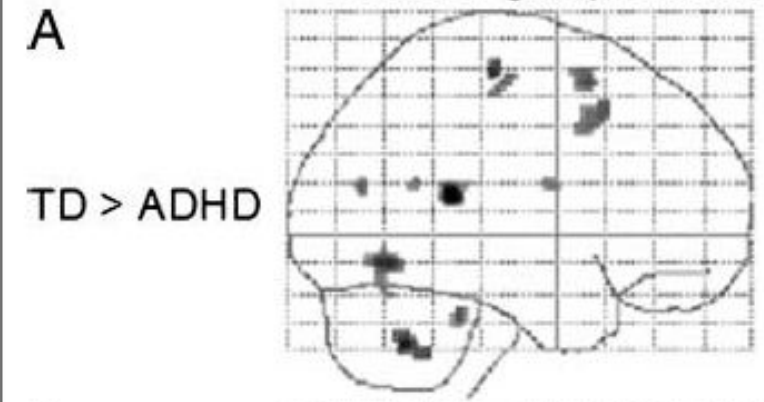

B

$\mathrm{ADHD}>\mathrm{TD}$

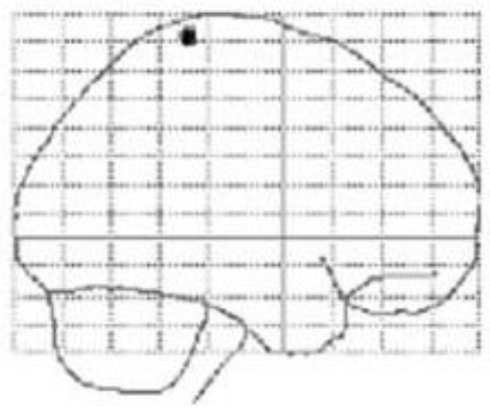

\section{Between-group contrasts for no-go-related activation}
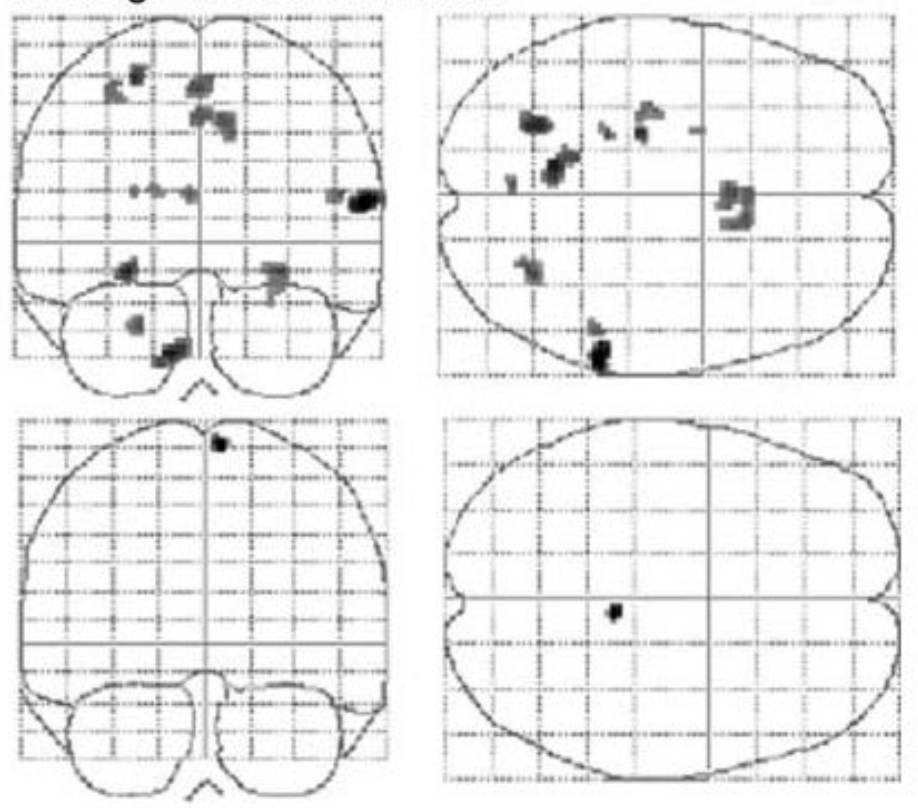

Figure 5.

Effects for paired $t$-test comparison of no-go effects between children with ADHD and TD children. Results are based on a random effects analysis of 25 subjects per group (uncorrected $p<.001$, cluster threshold $=5$ ). Transparent brain maps show regions where the time courses were significant covariates of fMRI signal changes in which no-go activation was greater in the TD group than in the ADHD group (upper row) or greater in the ADHD group than in the TD group (lower row). Neurologic convention is used (i.e., right = right hemisphere; projections looking rightward or into the page). As hypothesized main effects of TD > ADHD include the rostral supplementary motor areas ("pre-SMA," BA 6); other effects are seen in the right temporal parietal junction and fusiform gyrus and left cerebellar culmen, occipital lobe, and precentral gyrus. Main effect of ADHD > TD is seen in the right primary sensorimotor cortex (BA 3/4). 


\section{Table 1}

\section{Subject Characteristics and Behavioral Data}

\begin{tabular}{lccc}
\hline & ADHD & TD & Significance \\
\hline Age (years) & $10.8 \pm 1.2$ & $10.8 \pm 1.3$ & $n s$ \\
$\%$ Male & $60 \%$ & $60 \%$ & $n s$ \\
$\%$ Right-handed & $80 \%$ & $92 \%$ & $n s$ \\
Full-scale IQ & $113 \pm 12$ & $113 \pm 13$ & $n s$ \\
$\%$ Commission errors & $24.7 \pm 14.1$ & $22.0 \pm 11.5$ & $n s$ \\
$\%$ Omission errors & $4.2 \pm 4.4$ & $2.8 \pm 3.8$ & $n s$ \\
Reaction time (msec) & $445.4 \pm 118.2$ & $407.8 \pm 86.1^{a}$ & $n s$ \\
\hline
\end{tabular}

Subject characteristics and performance data for the 25 subjects with ADHD and the 25 TD control subjects. All data are provided as mean \pm standard deviation, unless otherwise specified. The groups were selected to be matched for sex, handedness, IQ, and percentage of commission errors.

Additionally, there were no significant differences in percentage of omission errors or reaction time to "go" stimuli.

${ }^{a}$ Based upon data from 24 control subjects; for one subject, reaction time data were not recorded. 


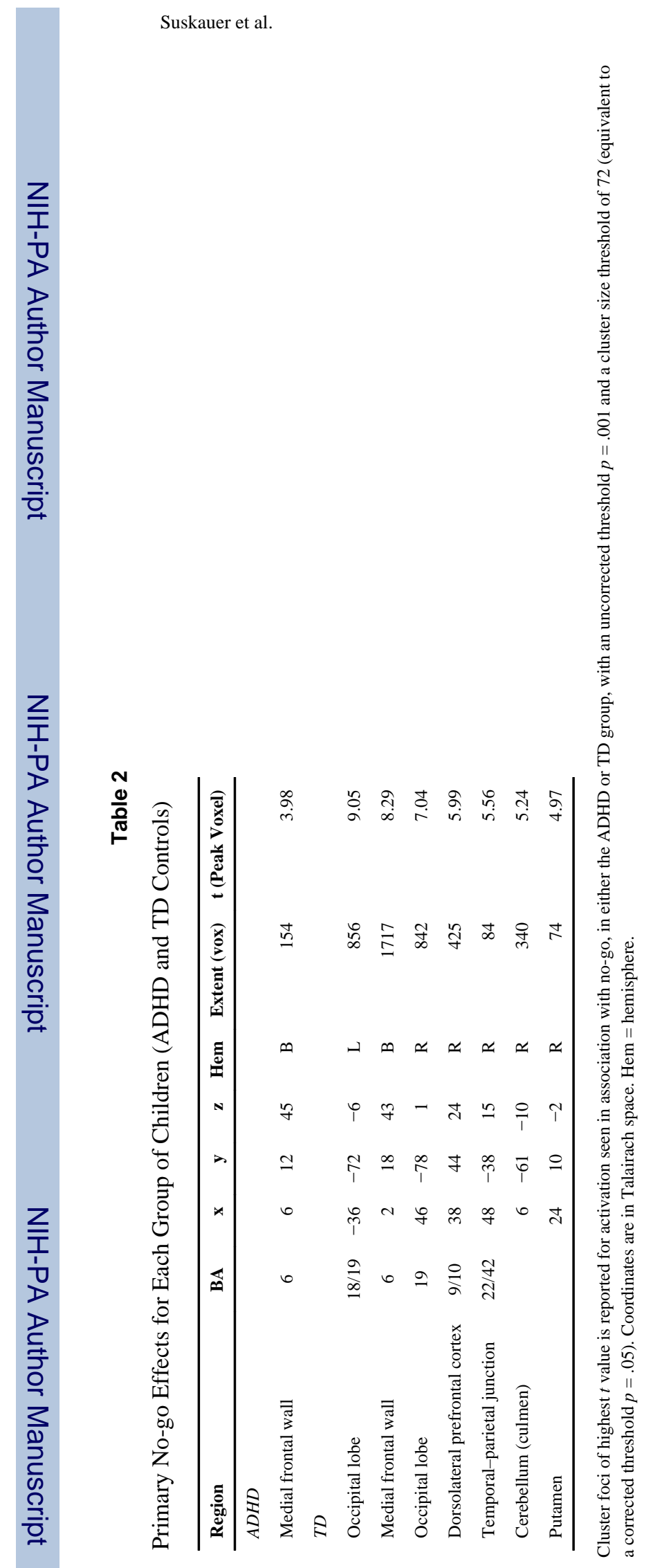

J Cogn Neurosci. Author manuscript; available in PMC 2010 July 2. 


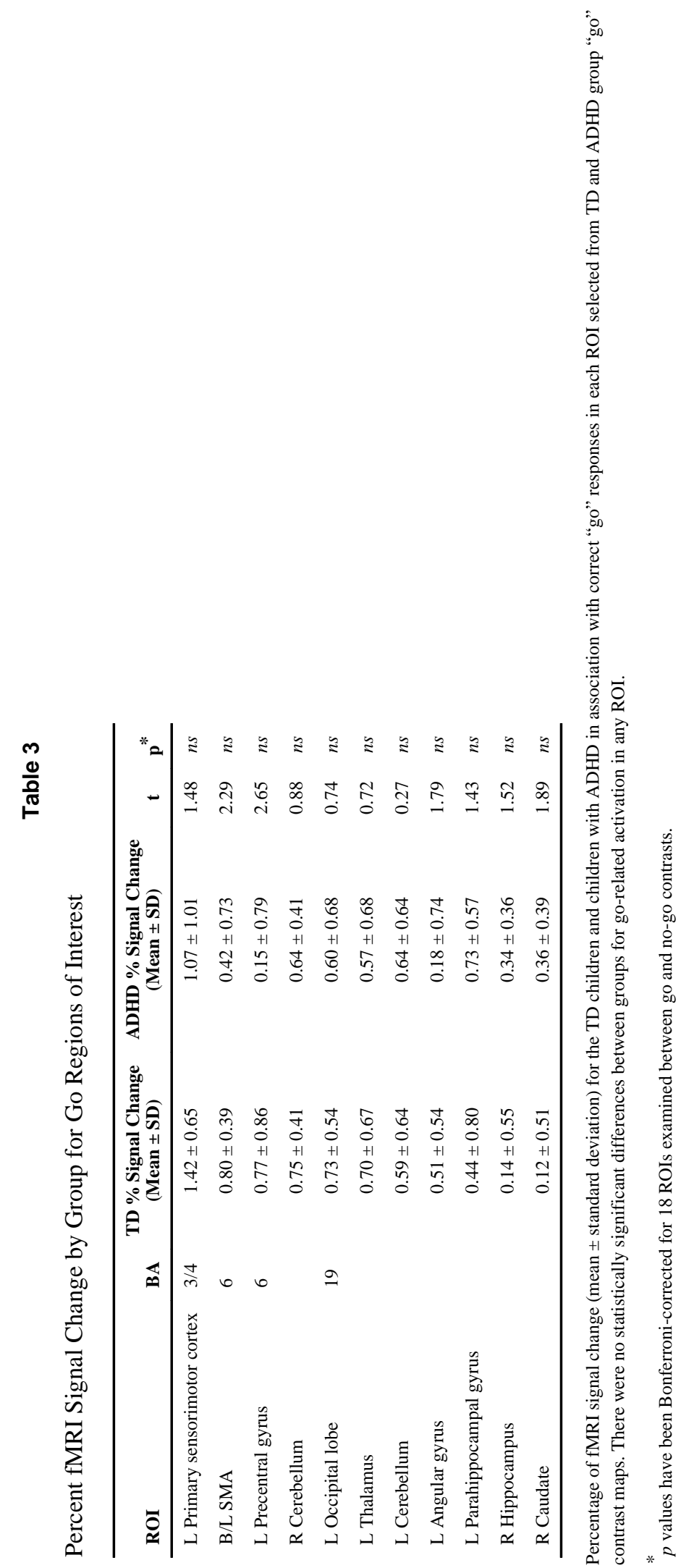

J Cogn Neurosci. Author manuscript; available in PMC 2010 July 2. 


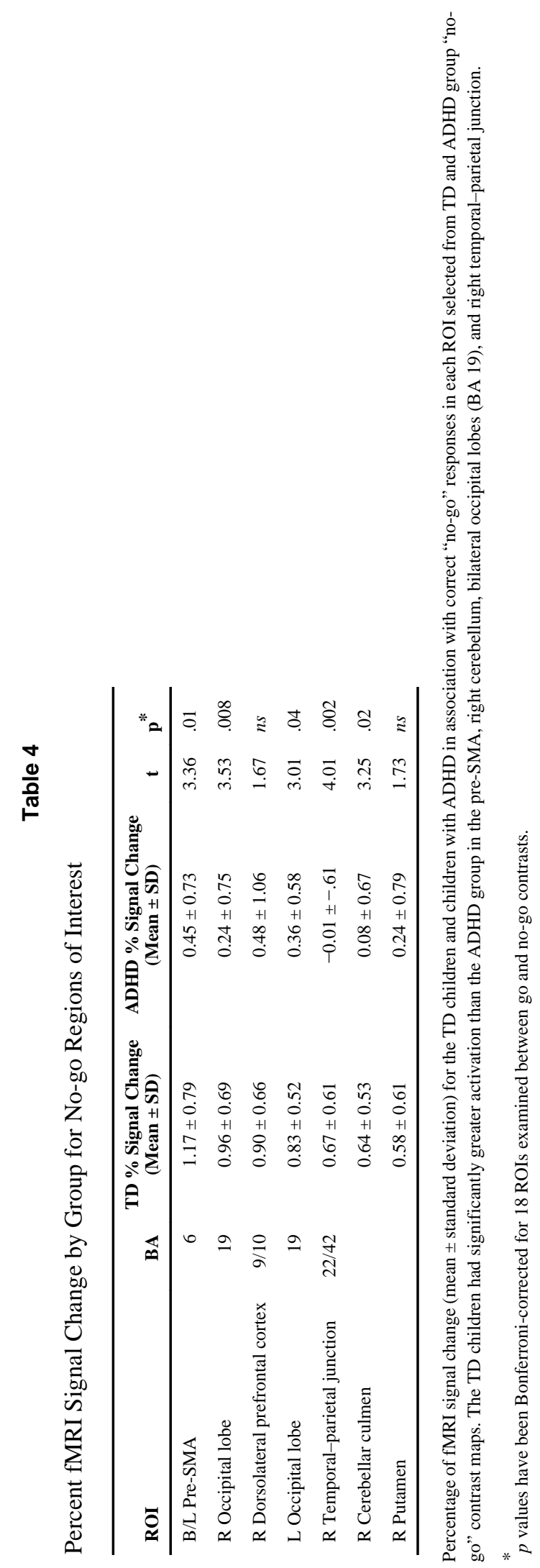




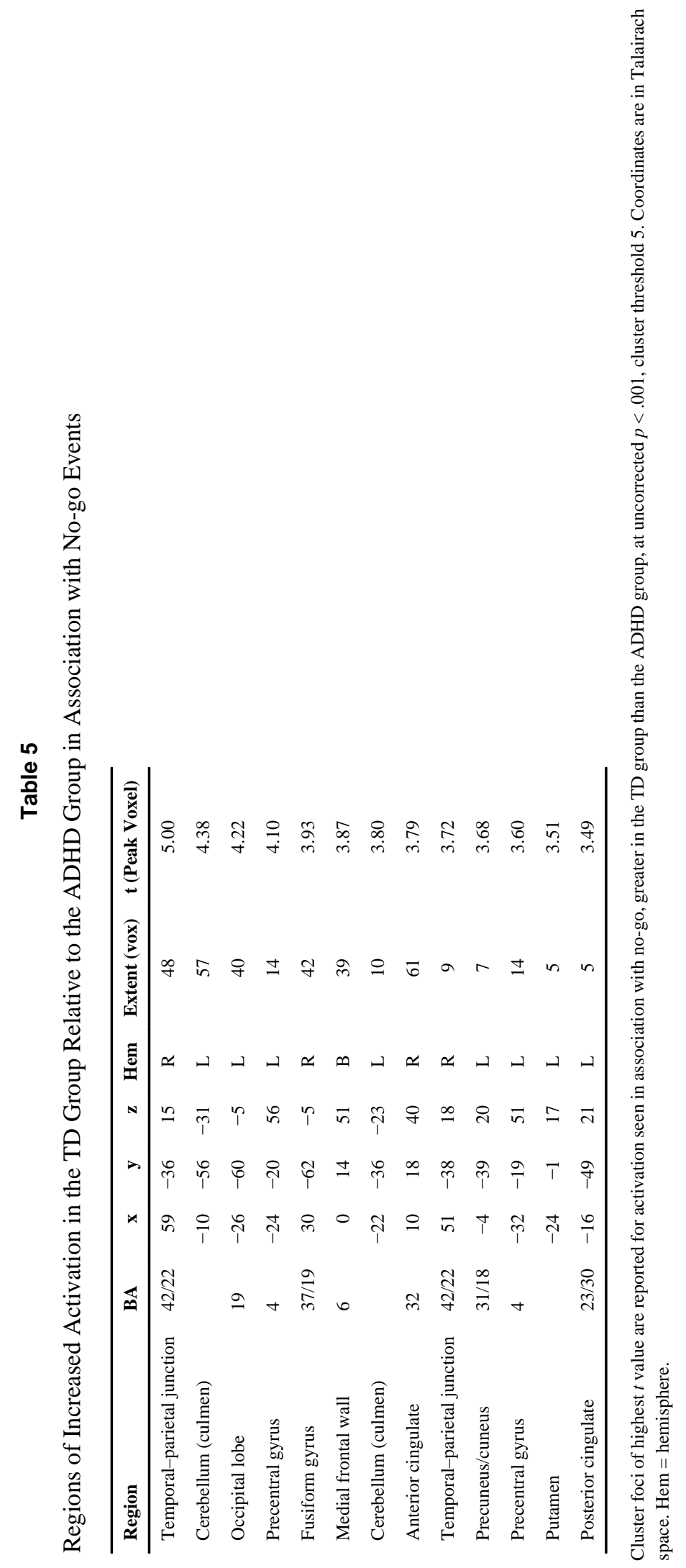




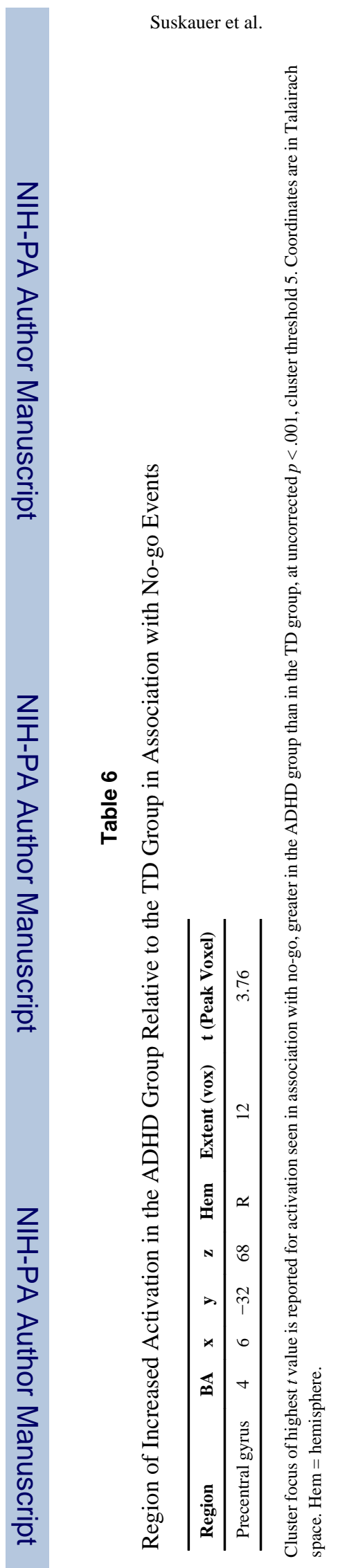

J Cogn Neurosci. Author manuscript; available in PMC 2010 July 2. 